\title{
Too many too soon - fever following PET CT
}

\author{
A Ghafur ${ }^{1,2^{*}}$, PR Vidyalakshmi ${ }^{2}$, K Mageshkumar $^{1}$, C Karupusamy $^{1}$, I Poojary ${ }^{3}$ \\ From 3rd International Conference on Prevention and Infection Control (ICPIC 2015) \\ Geneva, Switzerland. 16-19 June 2015
}

\section{Introduction}

Contaminated medical equipment and intravenous fluids are well known causative factors for procedure related bacteremia.

\section{Objectives}

Outbreak investigation we carried out in May 2014 in our PET CT unit.

\section{Methods}

Four of our patients who had PET CT in May 2014 presented with acute onset febrile illness shortly after the PET. All patients who had PET CT at that time were followed up. Three out of 4 patients grew Serratia in blood. Culture of medication samples including contrast and Saline bottles along with environmental samples and hands of staff were carried out.

\section{Results}

Four patients had fever following PET CT procedure in May 014. All four patients had a PET CT as a part of evaluation of malignancy. Three out of four had Serratia marsescens bacteremia with the same antibiogram.

Investigation for the possible source revealed that a normal saline bag (multi dose vial) that was used to reconstitute the contrast was the point source for the outbreak. Sample from the bag grew Serratia with the same antibiogram as that of the bacteremic patients. Although analysis by pulsed-field gel electrophoresis (PFGE) was not carried out, there was no other obvious source of contamination and the patients who developed bacteremia had no other intervention other than the PET scan. Post investigation corrective action was termination of the practice of using multi dose normal-saline bag and replacing those with single use saline flush for each patient. There were no further cases of Serratia bacteremia in PET CT unit since then. All the three patients recovered on antibiotic treatment.

${ }^{1}$ Infection Control, Apollo Speciality Hospitals, Chennai, India

Full list of author information is available at the end of the article

\section{Conclusion}

It is extremely important to be vigilant to detect outbreaks at the outset itself, especially in units where investigations are carried out in an out patient basis. The study also underscores the importance using single dose vials/single saline flush for all procedures including radiology ones.

\section{Disclosure of interest}

None declared.

\section{Authors' details}

${ }^{1}$ Infection Control, Apollo Speciality Hospitals, Chennai, India. ${ }^{2}$ Infectious Diseases, Apollo Speciality Hospitals, Chennai, India. ${ }^{3}$ Microbiology, Apollo Speciality Hospitals, Chennai, India.

Published: 16 June 2015

doi:10.1186/2047-2994-4-S1-P256

Cite this article as: Ghafur et al:: Too many too soon - fever following PET CT. Antimicrobial Resistance and Infection Control 2015 4(Suppl 1):P256.
Submit your next manuscript to BioMed Central and take full advantage of:

- Convenient online submission

- Thorough peer review

- No space constraints or color figure charges

- Immediate publication on acceptance

- Inclusion in PubMed, CAS, Scopus and Google Scholar

- Research which is freely available for redistribution
() Biomed Central

\section{Biomed Central}

